\title{
Patients' risk factors for periprosthetic joint infection in primary total hip arthroplasty: a meta-analysis of 40 studies
}

\author{
Xiaolei Ren ${ }^{\dagger}$, Lin Ling ${ }^{\dagger}$, Lin Qi, Zhongyue Liu, Wenchao Zhang, Zhimin Yang, Wanchun Wang, Chao Tu ${ }^{*}$ and
} Zhihong Li

\begin{abstract}
Background: Periprosthetic joint infection (PJI) is a catastrophic complication after total hip arthroplasty (THA). Our meta-analysis aimed to identify the individual-related risk factors that predispose patients to PJl following primary THA.

Methods: Comprehensive literature retrieval from Pubmed, Web of Science, and the Cochrane Library was performed from inception to Feb 20th, 2021. Patient-related risk factors were compared as per the modifiable factors (BMI, smoke and alcohol abuse), non-modifiable factors (gender, age), and medical history characteristics, such as diabetes mellitus (DM), avascular necrosis (AVN) of femoral head, femoral neck fracture, rheumatoid arthritis (RA), cardiovascular disease (CVD), and osteoarthritis (OA) etc. The meta-analysis was applied by using risk ratios with 95\% corresponding intervals. Sensitivity analysis and publication bias were performed to further assess the credibility of the results.

Results: Overall, 40 studies with 3,561,446 hips were enrolled in our study. By implementing cumulative metaanalysis, higher BMI was found associated with markedly increased PJI risk after primary THA [2.40 (2.01-2.85)]. Meanwhile, medical characteristics including DM [1.64 (1.25-2.21)], AVN [1.65 (1.07-2.56)], femoral neck fracture [1.75 (1.39-2.20)], RA [1.37 (1.23-1.54)], CVD [1.34 (1.03-1.74)], chronic pulmonary disease (CPD) [1.22 (1.08-1.37)], neurological disease [1.19 (1.05-1.35)], opioid use [1.53 (1.35-1.73)] and iron-deficiency anemia (IDA) [1.15 (1.131.17)] were also significantly correlated with higher rate of PJ. Conversely, dysplasia or dislocation [0.65 (0.45-0.93)], and OA [0.70 (0.62-0.79)] were protective factors. Of Note, female gender was protective for PJl only after longer follow-up. Besides, age, smoking, alcohol abuse, previous joint surgery, renal disease, hypertension, cancer, steroid use and liver disease were not closely related with PJI risk.

Conclusion: Our finding suggested that the individual-related risk factors for PJI after primary THA included high $\mathrm{BMI}, \mathrm{DM}, \mathrm{AVN}$, femoral neck fracture, RA, CVD, CPD, neurological disease, opioid use and IDA, while protective factors were female gender, dysplasia/ dislocation and OA.
\end{abstract}

Keywords: Periprosthetic joint infection, PJI, Total hip arthroplasty, THA, Risk factors

\footnotetext{
*Correspondence: tuchao@csu.edu.cn; lizhihong@csu.edu.cn

${ }^{+}$Xiaolei Ren and Lin Ling contributed equally to this work.

Department of Orthopaedics, Hunan Key Laboratory of Tumor Models and Individualized Medicine, The Second Xiangya Hospital, Central South

University, Changsha, Hunan, P.R. China
}

C C The Author(s). 2021 Open Access This article is licensed under a Creative Commons Attribution 4.0 International License, which permits use, sharing, adaptation, distribution and reproduction in any medium or format, as long as you give appropriate credit to the original author(s) and the source, provide a link to the Creative Commons licence, and indicate if changes were made. The images or other third party material in this article are included in the article's Creative Commons licence, unless indicated otherwise in a credit line to the material. If material is not included in the article's Creative Commons licence and your intended use is not permitted by statutory regulation or exceeds the permitted use, you will need to obtain permission directly from the copyright holder. To view a copy of this licence, visit http://creativecommons.org/licenses/by/4.0/ The Creative Commons Public Domain Dedication waiver (http://creativecommons.org/publicdomain/zero/1.0/) applies to the data made available in this article, unless otherwise stated in a credit line to the data. 


\section{Background}

Total hip arthroplasty (THA) has served as a successful elective surgical procedure that provides pain relief, restores joint function, and consequently enhances overall quality-of-life for millions of patients worldwide [1-3]. Although most patients benefit significantly from this advanced technique, there is still a minority of patients may suffer with device failure and thereby need additional operations $[4,5]$.

Periprosthetic joint infection (PII) is defined as infection involving the joint prosthesis and adjacent tissue. Its incidence is rare, which has been reported to range from 0.25 to $2.0 \%$ [6]. However, this morbidity may be devastating since it could jeopardize the results of the procedure, and even increase mortality $[1,7]$. Currently, tremendous efforts have been implemented and improvements in prosthesis material and surgical technique have been achieved in THA [8]. However, the incidence of PJI is still increasing worldwide alongside the uprising prevalence of revision surgery, morbid obesity epidemic, and other comorbidities. Treatments for PJI usually comprise prolonged systemic antibiotic treatment, debridement and revision, which may pose substantial burden of compromised function and impaired quality of life to the patients $[1,6]$. Moreover, patients with PJI are also associated with higher financial burden and greater medical resource utilization on the health care system $[4,9,10]$. Accordingly, identification of potential risk factors is of great importance for early detection and reduction of the deleterious consequence that attributed to PJI.

Nowadays, attention has been directed toward a plausible link between PJI and patients' individual risk factors in addition to the surgical- and hospitalrelated factors. More recently, substantial studies regarding the patient-related risk factors for PJI, such as obesity [4, 11-14], diabetes mellitus (DM) [14-17], male gender [18], rheumatoid arthritis (RA) [19, 20], and pulmonary diseases $[6,21]$, have been reported. However, the power of these studies may be impaired due to limited numbers of recruited patients, controversial results and range of potential risk factor studies. Besides, many of these risk factors were updated and even revised in recent years, which may consolidate or oppose against the previous results. Moreover, optimization of modifiable risk factor for PJI should be emphasized in clinical practice, while only limited studies have separated the modifiable and nonmodifiable risk factors to PJI. Given the limitations and remained discrepancies abovementioned, we took into account all the available literature and performed this updated meta-analysis, aiming to identify the potential individual risk factors for PJI undergoing primary THA.

\section{Materials and methods}

\section{Literature search strategy}

The MOOSE (Meta-analysis of Observational Studies in Epidemiology) and PRISMA (Preferred Reporting Items for Systematic reviews and meta-Analysis) 2020 Checklist were followed for the completion of this study [22, 23]. The study authors did not supply relevant information.

A computer-aided systematic literature retrieval was performed without restriction of language. Databases including Pubmed, Web of Science, and the Cochrane Library were searched from inception to Feb 20th, 2021, with search terms in variably combinations listed as follows: ("PJI" OR "periprosthetic joint infection" OR "prosthetic joint infection" or "deep infection" OR "deep surgical site infection") AND ("surgical" OR "surgical approach" OR "surgical incision" OR "incision") AND ("THA" OR "THR" OR "total hip arthroplasty" OR "total hip replacement"). Specially, only primary THAs were included in this meta-analysis.

Additionally, cross-references checking of each enrolled study were manually performed to identify possible additional articles.

Articles with potentially relevant titles and abstracts were screened and scored firstly by two independent investigators (CT and XLR). A third investigator (LQ) was consulted in the event of discrepancies between the two reviewers. Afterwards, the full manuscripts may be read if the studies could meet the inclusion criteria and the relevant information will be extracted.

\section{Study selection}

Included studies met the following criteria: 1) Quantitative observational studies including prospective cohorts or retrospective case-control trials; 2) Studies reported odds ratio (ORs) or risk ratio (RRs) for dichotomous risk factors and mean difference for continuous factors, or allowed calculation of ORs/ RRs from sufficient raw data; and 3) Risk factors must be demographic, comorbid, behavioral, infectious, native joint disease, other patient-related risk factors.

Exclusion criteria were as follows: 1) Insufficient data to estimate a pooled RR; 2) Duplicated data from the same authors, excluding the earlier and small studies; 3 ) Not focused on risk factors of PJI; 4) Documents without original raw data, such as correspondences, editorial materials, and reviews; 5) Not related to THA; and 6) Superficial infection.

\section{Data extraction and methodological quality assessment}

Two investigators carefully reviewed and screened the titles and abstracts independently to identify eligible studies as per the inclusion and exclusion criteria. The full text was read if necessary. Information items extracted 
from enrolled trials included as follows: first author, year of publication, location and investigation year of the study, study design, duration of follow-up (years), number of participants involved, confounders adjusted, age, and gender. Demographic risk factors, including behavioral risk factors, comorbid conditions, native joint disease, and other patient-related risk factors were searched for PJI.

Quality assessment was performed by using the Newcastle-Ottawa Scale (NOS) as previously described [24].

\section{Sensitivity analysis}

Sensitivity analysis was used to assess the robustness of the results and was planned based on the risk of bias assessment. A sensitivity analysis was performed for all the risk factors with substantial heterogeneity. Meta-regression was done for gender and DM.

\section{Statistical analysis}

This meta-analysis was conducted by using the STATA software (Stata 12.0) and Review Manager (RevMan 5.3). Due to variability in the populations and risk factors of included studies, random-effects models were adopted for meta-analysis. Data were categorized and analyzed by groups of risk factors.

The heterogeneity across the eligible studies was quantified using $I^{2}$ statistic. Meta-regression was done to explore heterogeneity and determine the causes of heterogeneity.

\section{Results}

\section{Search results and study identification}

A total of 4038 articles were collected by search strategy from PubMed, Web of science, and the Cochrane library. After assessment according to the inclusion eligibility criteria, 40 studies comprising 3,561,446 hips in total were finally recruited in this meta-analysis (Fig. 1). Articles with irrelevant topics like those without risk factors, reviews, meeting abstracts and papers with duplicate reports or unavailable data were excluded. Particularly, 75 studies which investigated risk factors of PJI both in total knee arthroplasty (TKA) and THA were excluded because the data of only primary THA could not be extracted. Among the included articles, eight were published in Asia-Pacific region, including Australia, Korea and Malaysia. Besides, seventeen studies were performed in the USA and sixteen in Europe including UK, Finland, Spain, Italy, Netherlands, Switzerland, Belgium and Portugal. All studies were published between 2001 and 2020 except two performed by Surin [25] and Vannini [15], which were published in 1983 and 1984, respectively. The investigation years ranged from 1969 to 2018. Study design included prospective case-control, prospective cohort, retrospective case-control and retrospective cohort studies. The mean \pm standard deviation of follow-up time was $2.92 \pm 2.62$ years.
The methodological quality was evaluated by NOS scores and calculated total quality scores ranged from 5 to 8 (Table S1). After qualitative synthesis, Yong et al. was excluded because of the low quality and low incidence of PJI, which might cause the bias [26]. All the characteristics details of included studies were demonstrated in Table 1.

\section{Effect of modifiable individual factors on the incidence of PJI}

Modifiable individual risk factors among studies were compared in terms of BMI (body mass index), smoke and alcohol abuse. Twenty-one studies were included in the BMI comparison. Subgroup analyses were further adopted according to different cut-off values, in which the patients were stratified by 30,35 and $40 \mathrm{~kg} / \mathrm{m}^{2}$ cutoff value group. All the pooled RRs and 95\% CI were shown in Table 2. In all the subgroups based on BMI cut-off value, the results indicated that higher BMI was associated with higher incidence of PJI (Fig. 2A). The pooled RR $(95 \% \mathrm{CI})$ of smoke and alcohol abuse ( $>45 \mathrm{~g} /$ day males, $>30 \mathrm{~g} /$ day females) comparisons were 1.24 (0.85-1.82) (Fig. 2B) and 1.69 (0.76-3.80) (Fig. 2C), respectively, which suggested that smoke and alcohol abuse were not risk factors relating to PJI for THA.

The heterogeneity in BMI and smoke analysis groups were not significant $\left(I^{2}<50 \%\right)$. Although alcohol comparisons results exhibited significant heterogeneity $\left(I^{2}=\right.$ $80.0 \%$ ), the few numbers of the included studies were not enough to analyze the source of heterogeneity.

\section{Effect of non-modifiable individual factors on the incidence of $\mathrm{PJI}$}

Gender and age were analyzed as non-modifiable individual factors to explore their effects on the incidence of PJI. The meta-analysis of gender factor included data from 19 studies. The forest plot of overall pooled RRs (Fig. 3A) showed significant difference in the prevalence of PJI between the male and female groups ( $R R=1.17,95 \% \mathrm{CI}: 1.03-1.32)$ under a random-effects model, which suggested that female maybe a protective role of PJI for THA. Since obvious heterogeneity was observed $\left(I^{2}=83.9 \%, p<0.001\right)$, subgroup analyses were further performed to identify the possible varieties, in which the patients were stratified by location, follow-up duration (years), study design and confounders adjustment (Table 3). Univariate meta-regressions showed significant relevance between the heterogeneity of gender factor and study design $(p=0.078)$. Seven studies from prospective studies group revealed that male had higher risk suffering from PJI than female $(1.39,1.13-1.72)$. Whereas, retrospective study group still had no significant difference (1.04, 0.89-1.23) (Fig. 3C). Besides, female gender also was a protective factor (1.16, 1.02-1.32) of PJI after THA in North American people, as shown in Figure S1A. 


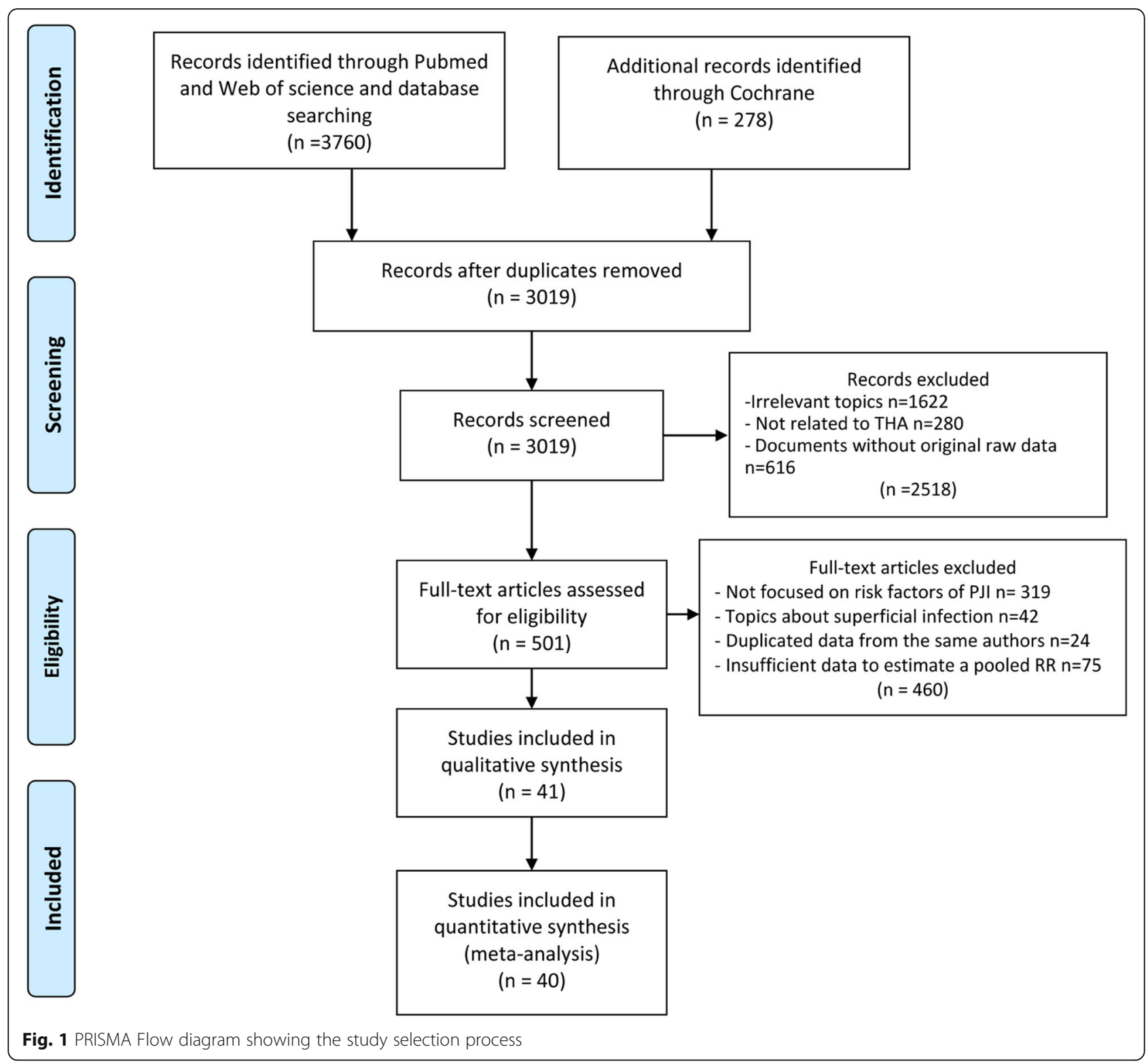

Seven studies reported data regarding relevance between different age stages and the incidence of PJI. The overall pooled RR and 95\% CI $(0.85,0.71-1.01)$ were calculated using a random model and results exhibited heterogeneity $\left(I^{2}=59.0 \%, P=0.023\right)$ in some degree (Fig. $3 \mathrm{~B})$. It indicates that more evidence is needed to confirm age as a risk factor of PJI.

\section{Effect of medical history characteristics on the incidence of PJI}

Seventeen medical history characteristics reported in studies were associated with PJI, and details were presented in Table 4. Sixteen studies exhibited the effect of diabetes mellitus (DM) on the incidence of PJI (Fig. 4A). The overall pooled RR and corresponding 95\% CI (1.64,
1.22-2.21) was calculated using a random model and results showed obvious heterogeneity $\left(I^{2}=93.5 \%, p<\right.$ 0.001). Similarly, subgroup analyses were performed to find potentially explicable variety of DM (Figure S2). Furthermore, meta-analysis results indicated that avascular necrosis (AVN) of femoral head (Fig. 4B), femoral neck fracture (Fig. 4C), rheumatoid arthritis (RA) (Fig. 4D), cardiac vascular disease (CVD) (Fig. 4E), chronic pulmonary disease (Fig. 4F), neurological diseases including dementia and Parkinson's disease (Fig. 4G), opioid use (Fig. 4H) and iron-deficiency anemia (IDA) (Fig. 4I) were significant risk factors of the incidence of PJI after THA. While the comparisons about osteoarthritis (OA) vs. non-OA, and dysplasia or dislocation vs. non groups showed the opposite effects on PJI, implicating 
Table 1 Demographic characteristics of the enrolled studies

\begin{tabular}{|c|c|c|c|c|c|c|c|c|}
\hline ID & Authors (Year) & Location & $\begin{array}{l}\text { Investigation } \\
\text { years }\end{array}$ & Study design & $\begin{array}{l}\text { Follow-up } \\
\text { years }\end{array}$ & $\begin{array}{l}\text { Sample } \\
\text { size, } \mathrm{n}\end{array}$ & $\begin{array}{l}\text { Confounders } \\
\text { adjusted }\end{array}$ & NOS \\
\hline 1 & Bozic, et al. (2014) [27] & $\begin{array}{l}\text { North } \\
\text { America }\end{array}$ & 1990-2011 & $\begin{array}{l}\text { Prospective case- } \\
\text { control }\end{array}$ & 3.7 & 587 & Multivariate & 7 \\
\hline 2 & Burn, et al. (2018) [19] & Europe & 1995-2014 & Retrospective cohort & 0.25 & 10,260 & Multivariate & 7 \\
\hline 3 & Chee, et al. (2010) [28] & Europe & 1998-2003 & Prospective cohort & 5 & 110 & Univariate & 5 \\
\hline 4 & Choong, et al. (2007) [29] & Asia-Pacific & 1998-2004 & Retrospective cohort & 3.5 & 819 & Univariate & 5 \\
\hline 5 & $\begin{array}{l}\text { Cordero-Ampuero, et al. } \\
\text { (2010) [30] }\end{array}$ & Europe & 1997-2007 & $\begin{array}{l}\text { Prospective case- } \\
\text { control }\end{array}$ & 2.3 & 124 & Univariate & 5 \\
\hline 6 & Dale, et al. (2011) [31] & Europe & 2005-2009 & Prospective cohort & 1 & 5540 & Multivariate & 7 \\
\hline 7 & Davis, et al. (2011) [32] & Europe & 1998-2005 & Prospective cohort & 5 & 1617 & Multivariate & 8 \\
\hline 8 & de Boer, et al. (2001) [33] & Europe & 1996-1999 & Retrospective cohort & 1 & 12,588 & Univariate & 6 \\
\hline 9 & Dowsey, et al. (2008) [12] & Asia-Pacific & 1998-2005 & Retrospective cohort & 1 & 1207 & Univariate & 5 \\
\hline 10 & Gittings, et al. (2017) [34] & $\begin{array}{l}\text { North } \\
\text { America }\end{array}$ & $2009-2014$ & Retrospective cohort & 1 & 33 & $\begin{array}{l}\text { Univariate/ } \\
\text { multivariate }\end{array}$ & 6 \\
\hline 11 & Gonzalez, et al. (2018) [35] & Europe & $1996-2013$ & Prospective cohort & 5.6 & 5198 & Multivariate & 7 \\
\hline 12 & Hartford, et al. (2020) [36] & $\begin{array}{l}\text { North } \\
\text { America }\end{array}$ & - & Retrospective cohort & 1 & 1808 & Multivariate & 6 \\
\hline 13 & Huotari, et al. (2007) [37] & Europe & $2001-2004$ & Retrospective cohort & 1 & 5614 & Univariate & 5 \\
\hline 14 & Jamsen, et al. (2012) [14] & Europe & $2002-2008$ & Retrospective cohort & 1 & 3266 & Multivariate & 7 \\
\hline 15 & Jung, et al. (2017) [38] & Asia-Pacific & $2013-2015$ & Retrospective cohort & 0.25 & 10,690 & Multivariate & 6 \\
\hline 16 & Kildow, et al. (2017) [16] & $\begin{array}{l}\text { North } \\
\text { America }\end{array}$ & $2005-2012$ & $\begin{array}{l}\text { Retrospective case- } \\
\text { control }\end{array}$ & 2 & 61,778 & Multivariate & 6 \\
\hline 17 & Kurtz, et al. (2018) [39] & $\begin{array}{l}\text { North } \\
\text { America }\end{array}$ & $2005-2015$ & $\begin{array}{l}\text { Retrospective case- } \\
\text { control }\end{array}$ & 4.7 & $1,158,742$ & Multivariate & 7 \\
\hline 18 & $\begin{array}{l}\text { Lenguerrand, et al. (2018) } \\
\text { [40] }\end{array}$ & Europe & 2003-2013 & Prospective cohort & 4.6 & 623,253 & Multivariate & 8 \\
\hline 19 & Lubbeke, et al. (2007) [41] & Europe & 1996-2005 & Prospective cohort & 5 & 2495 & Multivariate & 7 \\
\hline 20 & Maoz, et al. (2015) [42] & $\begin{array}{l}\text { North } \\
\text { America }\end{array}$ & $2009-2011$ & Retrospective cohort & 2 & 3672 & Multivariate & 6 \\
\hline 21 & Marjo, et al. (2007) [43] & Europe & $2000-2002$ & Prospective cohort & 1 & 1922 & Multivariate & 7 \\
\hline 22 & Matar, et al. (2020) [44] & $\begin{array}{l}\text { North } \\
\text { America }\end{array}$ & $2012-2018$ & Retrospective cohort & 1 & 7270 & Multivariate & 7 \\
\hline 23 & Mclntosh, et al. (2006) [45] & $\begin{array}{l}\text { North } \\
\text { America }\end{array}$ & 1998-2002 & Retrospective cohort & 2.7 & 448 & Multivariate & 6 \\
\hline 24 & Meermans, et al. (2012) [46] & Europe & 1998-2006 & Retrospective cohort & 5.9 & 364 & Univariate & 5 \\
\hline 25 & Muilwijk, et al. (2006) [47] & Europe & $1996-2003$ & Retrospective cohort & 1 & 26,127 & Multivariate & 7 \\
\hline 26 & Namba, et al. (2012) [48] & $\begin{array}{l}\text { North } \\
\text { America }\end{array}$ & $2001-2009$ & Retrospective cohort & 1 & 30,491 & $\begin{array}{l}\text { Univariate/ } \\
\text { multivariate }\end{array}$ & 7 \\
\hline 27 & Ong, et al. (2009) [49] & $\begin{array}{l}\text { North } \\
\text { America }\end{array}$ & 1997-2006 & Prospective cohort & 10 & 39,929 & Multivariate & 7 \\
\hline 28 & Peel, et al. (2011) [50] & Asia-Pacific & 2000-2007 & $\begin{array}{l}\text { Prospective case- } \\
\text { control }\end{array}$ & 1 & 108 & Univariate & 5 \\
\hline 29 & Rondon, et al. (2018) [51] & $\begin{array}{l}\text { North } \\
\text { America }\end{array}$ & $2000-2016$ & $\begin{array}{l}\text { Retrospective case- } \\
\text { control }\end{array}$ & 5.3 & 145 & Univariate & 6 \\
\hline 30 & Sequeira, et al. (2020) [52] & $\begin{array}{l}\text { North } \\
\text { America }\end{array}$ & 2005-2014 & Retrospective cohort & 1 & 741,078 & Multivariate & 6 \\
\hline 31 & Sequeira,S et al. (2020) [53] & $\begin{array}{l}\text { North } \\
\text { America }\end{array}$ & $2005-2014$ & Retrospective cohort & 1 & 483,405 & Multivariate & 6 \\
\hline 32 & Smith, et al. (2018) [54] & Asia-Pacific & $2000-2014$ & Prospective cohort & 1 & 91,585 & Multivariate & 7 \\
\hline 33 & Sodhi,N et al. (2020) [55] & North & $2005-2014$ & Retrospective cohort & 2 & 14,944 & Univariate & 6 \\
\hline
\end{tabular}


Table 1 Demographic characteristics of the enrolled studies (Continued)

\begin{tabular}{|c|c|c|c|c|c|c|c|c|}
\hline \multirow[t]{2}{*}{ ID } & \multirow[t]{2}{*}{ Authors (Year) } & \multirow{2}{*}{$\begin{array}{l}\text { Location } \\
\text { America }\end{array}$} & \multirow[t]{2}{*}{$\begin{array}{l}\text { Investigation } \\
\text { years }\end{array}$} & \multirow[t]{2}{*}{ Study design } & \multirow[t]{2}{*}{$\begin{array}{l}\text { Follow-up } \\
\text { years }\end{array}$} & \multirow[t]{2}{*}{$\begin{array}{l}\text { Sample } \\
\text { size, } n\end{array}$} & \multirow[t]{2}{*}{$\begin{array}{l}\text { Confounders } \\
\text { adjusted }\end{array}$} & \multirow[t]{2}{*}{ NOS } \\
\hline & & & & & & & & \\
\hline 34 & Sodhi, et al. (2020) [56] & $\begin{array}{l}\text { North } \\
\text { America }\end{array}$ & 2005-2014 & Retrospective cohort & 2 & 162,489 & Multivariate & 6 \\
\hline 35 & Song, et al. (2012) [57] & Asia-Pacific & 2006-2009 & Retrospective cohort & 1 & 3422 & $\begin{array}{l}\text { Univariate/ } \\
\text { multivariate }\end{array}$ & 7 \\
\hline 36 & Surin, et al. (1983) [25] & Europe & 1970-1977 & Retrospective cohort & $3-10$ & 803 & Univariate & 5 \\
\hline 37 & Tai, et al. (2014) [58] & Asia-Pacific & 1997-2003 & Prospective cohort & 10 & 1420 & Univariate & 5 \\
\hline 38 & $\begin{array}{l}\text { Triantafyllopoulos, et al. } \\
\text { (2018) [59] }\end{array}$ & $\begin{array}{l}\text { North } \\
\text { America }\end{array}$ & 1999-2013 & Retrospective cohort & 8.6 & 36,494 & $\begin{array}{l}\text { Univariate/ } \\
\text { multivariate }\end{array}$ & 7 \\
\hline 39 & Vannini, et al. (1984) [15] & Europe & 1969-1979 & $\begin{array}{l}\text { Prospective case- } \\
\text { control }\end{array}$ & 2.9 & 1042 & Univariate & 5 \\
\hline 40 & Wilson, et al. (2020) [60] & $\begin{array}{l}\text { North } \\
\text { America }\end{array}$ & 2009-2017 & Retrospective cohort & 1 & 8559 & Multivariate & 6 \\
\hline
\end{tabular}

that OA and dysplasia/dislocation could be served as protective factors for PJI (Fig. 5). Additionally, there was not enough evidence to prove the previous joint surgery, renal disease, hypertension, cancer, steroid use history and liver disease associating with PJI (Figure S3). The details of the above pooled RRs, 95\% CI and heterogeneity analysis were revealed in Table 4.

\section{Sensitivity analysis}

Sensitivity analysis was performed to assess whether the pooled results were credible. In BMI comparison, sensitivity analysis illustrated that excluding the study by Matar, et al. [36] changed the original results and the modified pooled RR $(95 \% \mathrm{CI})$ was 2.15 (1.88-2.46) after excluding this study (Fig. 6A). However, the significance of BMI in predicting PJI risk was not altered, indicating that high BMI was still positively correlated with increased PJI risk. Sensitivity analysis of gender factor was shown in Figure S1D.

\section{Publication Bias}

Funnel plots, Egger's and Begg's tests were performed to evaluate the publication bias of the included studies, visually and statistically. BMI comparison had publication bias ( $P=0.046$ with Egger's test). RR and 95\% CI
$(2.228,1.867-2.660)$ were modified with random trimming and filled method (Fig. 6B, C). In addition, Gender comparison did not have publication bias $(P=0.378$ with Begg's test) and DM comparison also did not have publication bias $(P=0.252$ with Begg's test). (Figure S1E, S2E).

\section{Discussion}

Our meta-analysis focused on the patient-related factors associated with PJI, other than surgical- or hospitalrelated factors. The main finding of this meta-analysis was that the high BMI was the main risk factor for PJI. Additionally, DM and other comorbidities, such as AVN, RA, CVD, CPD, neurological disease, opioid use and IDA were also pivotal risk factors for PJI. In contrast, dysplasia or dislocation, OA were protective factors. Besides, female gender was protective after long follow-up duration ( $\geq 3$ years). Moreover, age, smoking, alcohol abuse and other medical history such as previous joint surgery, renal disease, hypertension, cancer, steroid use and liver disease were not correlated with risk of PJI.

Obesity poses a major health challenge worldwide [1]. Consistent with previous finding [18, 61], our data showed that patients with a BMI greater than 40,35 , or 30 had a 2.99, 2.46, or 2.02-fold higher risk of PJI

Table 2 Modifiable risk factors for periprosthetic joint infection and the outcomes of meta-analysis

\begin{tabular}{llll}
\hline Comparisons & Number of studies & RR (95\% Cl) & $\begin{array}{c}\text { Heterogeneity } \\
\boldsymbol{l}^{2}, \boldsymbol{p} \text {-value* }\end{array}$ \\
\hline $1 . \mathrm{BMI}\left(\mathrm{kg} / \mathrm{m}^{2}\right)$ & 20 & $2.40(2.01-2.85)$ & $42.4 \%, 0.024$ \\
$\mathrm{BMI} \geq 30 \mathrm{vs} . \mathrm{BMl}<30$ & 10 & $2.01(1.83-2.22)$ & $0.0 \%, 0.495$ \\
$\mathrm{BMI} \geq 35 \mathrm{vs} . \mathrm{BMl}<35$ & 4 & $2.46(1.73-3.51)$ & $0.0 \%, 0.796$ \\
$\mathrm{BMI} \geq 40 \mathrm{vs} . \mathrm{BMl}<40$ & 6 & $2.99(1.59-5.61)$ & $74.0 \%, 0.002$ \\
2. Smoke vs. non & 6 & $1.24(0.85-1.82)$ & $0.0 \%, 0.756$ \\
3. Alcohol abuse vs. non & 3 & $1.69(0.76-3.80)$ & $80.0 \%, 0.007$ \\
\hline
\end{tabular}




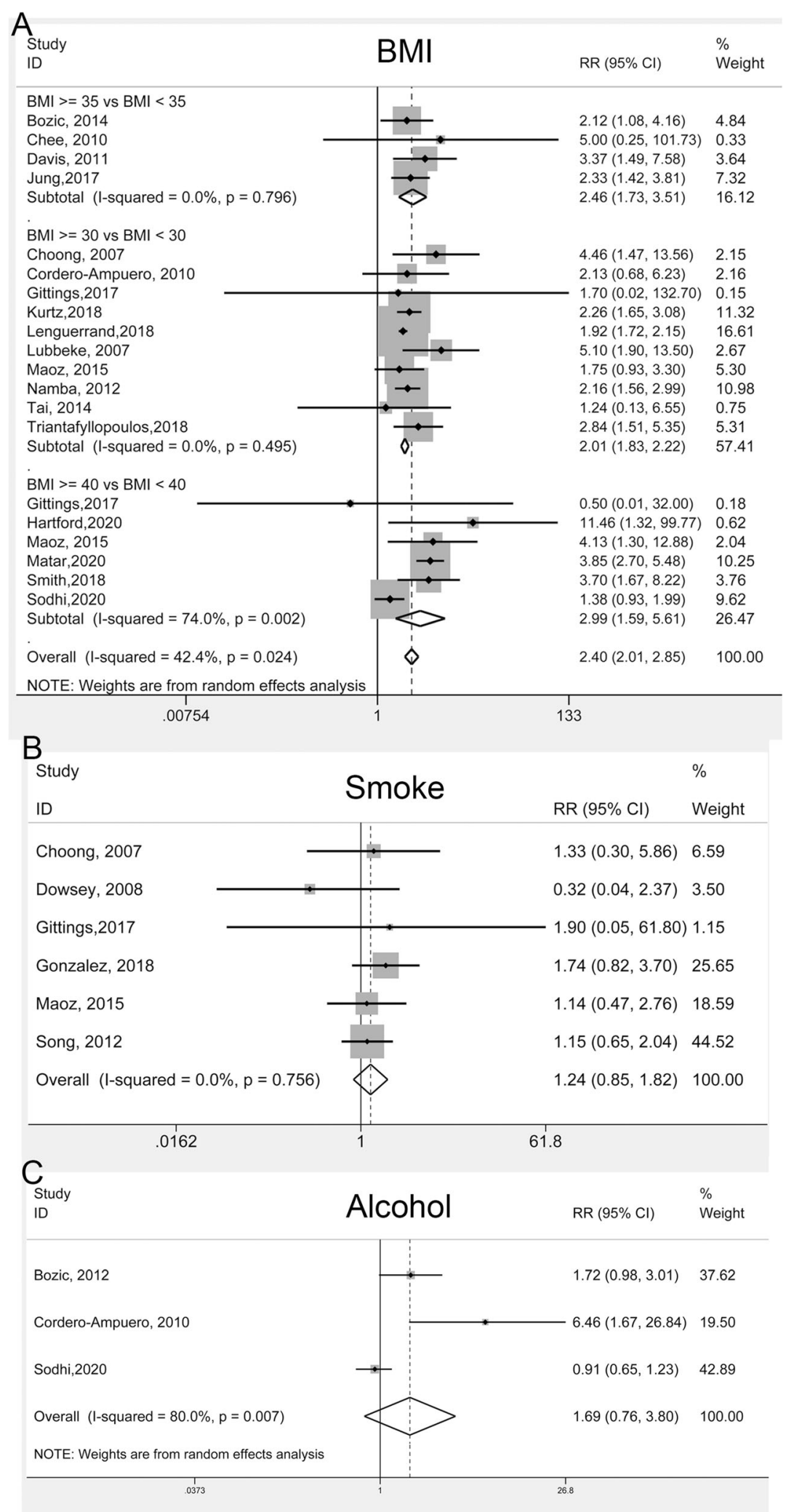

Fig. 2 (See legend on next page.) 
(See figure on previous page.)

Fig. 2 Forest plots of the meta-analysis of modifiable risk factors, including BMI (A), smoking (B), and alcohol abuse (C) as risk factors for periprosthetic joint infection (PJI) following total hip arthroplasty (THA). The diamond squares represent the pooled risk ratios (RRs) and corresponding 95\%

confidence intervals $(\mathrm{Cls})$, while the squares and horizontal lines demonstrate the proportional weight and $95 \% \mathrm{Cl}$ of each included study, respectively

compared with those counterparts with less BMI, respectively. Obese patients are more prone to increased risk of PJI in the peri-operative setting, which may be attributed to prolonged operative and anesthetic time, higher colonization risk for C. avidum in the groin [11], longer hospital stay and high readmission rates within 30 days [9]. Besides, being obese is usually correlated with higher presence of other commodities including metabolic syndrome, wound dehiscence, and heart disease [1]. Notably, we found that the PJI risk increased exponentially along with BMI value. Similarly, Xu C et al. demonstrated that each one-unit increase in BMI was correlated with an $8 \%$ higher risk of PJI [4], thus the morbidly obese patients (BMI $>40 \mathrm{~kg} / \mathrm{m}^{2}$ ) may have the highest likelihood of complications [13]. Another study also confirmed that all-cause revision rater after primary TJA doubled in patients with BMI $\geq 35 \mathrm{~kg} / \mathrm{m}^{2}$, and even tripled in morbidly obese patients when compared with the controls [7, 62]. Accordingly, the increased risk of obesity should be weighed against the benefits of THA [7].

The relationship between DM and PJI has been wellestablished with a projected increase for years $[18,61$, 63]. Our study showed that, comparing with non-DM patients, those undergoing THA with DM carried 1.69fold greater risk of PJI $(1.69,1.26-2.28)$. Further stratified analyses, such as location, study design or analyses method, did not alter the unfavorable predictive value of DM on PJI risk. Epidemiological studies have identified that DM predisposes patients to PJI, probably due to increased infection rate of bacteria, impaired immune response, and postoperative hyperglycemia [64]. HbA1c is a widely used biomarker for diagnosis and monitoring of type 2 DM [17]. Recently, Cancienne JM et al. reviewed 7736 patients who underwent THA, and identified that HbA1c of $7.5 \mathrm{mg} / \mathrm{dl}$ could serve as a threshold for prediction of PJI after THA [10].

Both two studies reported the association between AVN or femoral neck fracture and PJI, and the pooled results indicated a 1.65 or 1.75 -times increased risk of PJI than non-group, respectively. In contrast, four studies demonstrated the relationship between OA and PJI risk, and the calculated RR with corresponding $\mathrm{CI}$ was 0.70 (0.62-079), suggesting a protective role of OA in PJI. It is generally accepted that patients underwent THA for AVN are more likely to have readmission and surgical complications including bleeding transfusion [65]. Meanwhile, patients with femoral neck fracture undergoing THA also confer to higher rate of dislocation, infection and reoperation [66], which may be accountable for the increased risk of PJI [67]. OA refers to a common degenerative joint disease, and contribute to a majority cause for THA. However, compared with other commodities, patients with OA seem to have decreased occurrence of PJI after surgery. Another meta-analysis consisting of 37 studies reached a similar conclusion, showing that OA was protective factor in predicting PJI after THA/TKA [18]. Besides, Mayers W et al. searched the patients' profiles with primary THA in US from 2001 to 2010, and found that patient underwent THA for OA have lesser medical complications and lower incidence for myocardial infarction than those with AVN [68].

RA and CVD have been reported as independent risk factors for PJI [3, 69]. Consistently, our results showed that PJI incidence were 1.37 or 1.34 times higher in patients reporting a history of RA or CVD, respectively. Patients with RA are more susceptible to PJI thought to be secondary to immune-suppressive therapies and poor nutritional conditions $[18,20]$. Meanwhile, patient with CVD are recommended to receive aggressive anticoagulation therapy, such as aspirin or warfarin, may markedly increases risk of bleeding and wound hematoma after THA $[1,69]$, and thereby increase PJI rate [18].

Moreover, our study showed that patients with chronic pulmonary disease had 1.22-fold higher risk and with neurological disease had 1.19-fold higher risk (1.19, 1.05-1.35) of PJI when compared with non-group, which is in accordance with the published literature $[3,18,69]$. A meta-analysis conducted by Resende VAC et al. [18] showed that chronic lung disease significantly increased the risk for PJI after TJA. In addition to THA/TKA, another large multi-institutional retrospective study comprising 6977 patients also revealed a significant positive association between chronic lung disease and total ankle arthroplasties (TAA) [70]. More recently, a metaanalysis with eight studies enrolled further confirmed that increased risk of PJI following TAA for patients with lung disease [71].

Gender shows conflicting results among the selected studies. A number of studies have demonstrated that male patients are more vulnerable to PJI compared to women $[18,67]$. Whereas other studies have refuted this, claiming women had an elevated risk of deep infection than men $[48,72]$. Our results showed that gender was markedly correlated with PJI risk $(1.17,1.03-1.32)$ and female maybe a protective factor of PJI after THA. It is worth noting that male patients seem to coincide with 


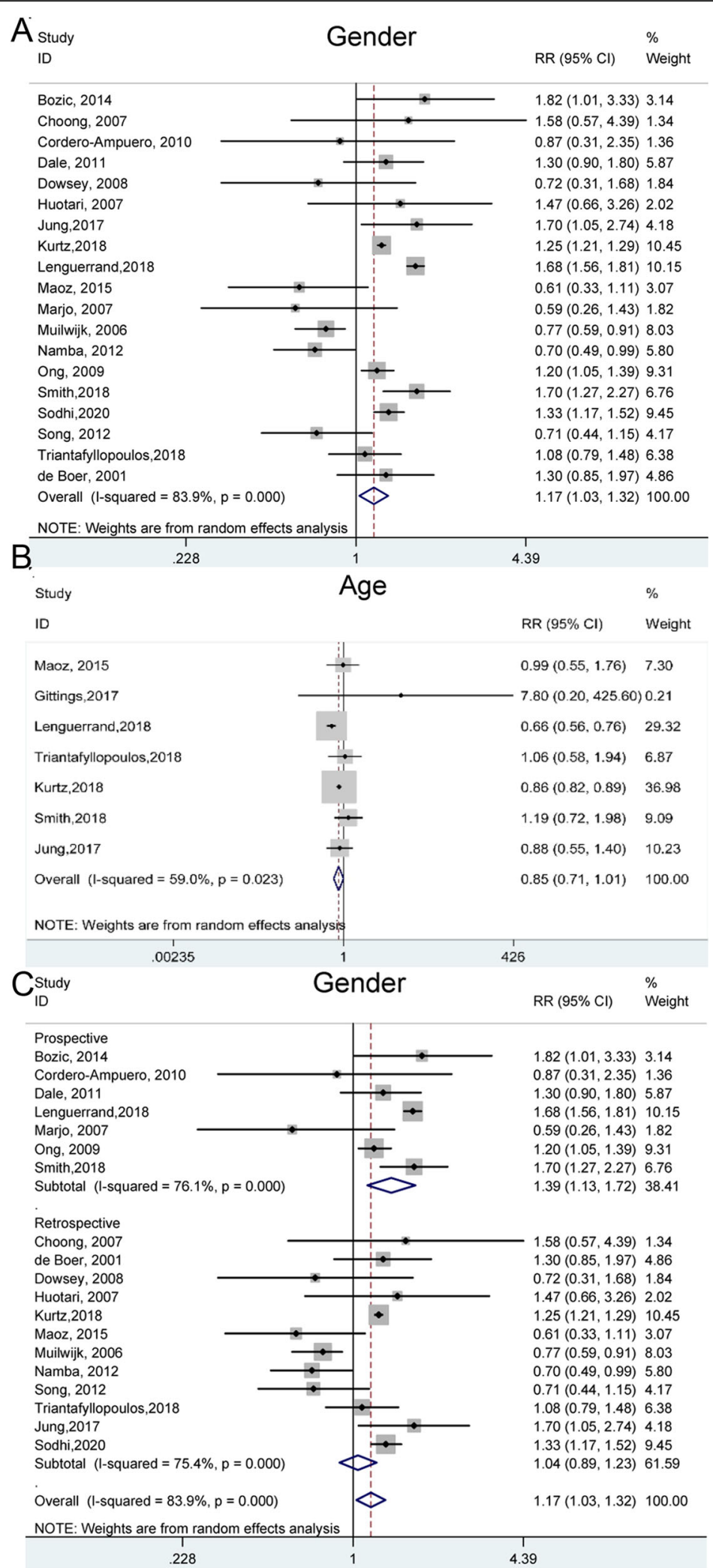

Fig. 3 Forest plots of the meta-analysis of non-modifiable risk factors, including gender (A) and age (B) as risk factors for PJI following THA. Subgroup analysis for gender with different study design $(\mathbf{C})$ were further shown to identify the possible association between gender with PJ 
Table 3 Non- modifiable risk factors for periprosthetic joint infection and the outcomes of meta-analysis

\begin{tabular}{|c|c|c|c|c|}
\hline Comparisons & Number of studies & $\operatorname{RR}(95 \% \mathrm{Cl})$ & $\begin{array}{l}\text { Heterogeneity } \\
I^{2}, p \text {-value* }\end{array}$ & $p$-value \\
\hline 1. Gender & 19 & $1.17(1.03-1.32)$ & $83.9 \%,<0.001$ & \\
\hline 1.1 Location & & & & 0.804 \\
\hline North America & 7 & $1.16(1.02-1.32)$ & $68.8 \%, 0.004$ & \\
\hline Asia-Pacific & 5 & $1.22(0.80-1.87)$ & $67.7 \%, 0.015$ & \\
\hline Europe & 7 & $1.13(0.78-1.63)$ & $88.5 \%,<0.001$ & \\
\hline 1.2 Follow-up years & & & & 0.787 \\
\hline$\geq 3$ & 6 & $1.35(1.13-1.62)$ & $91.0 \%,<0.001$ & \\
\hline$<3$ & 13 & $1.16(1.00-1.33)$ & $56.6 \%, 0.006$ & \\
\hline 1.3 Study design & & & & 0.078 \\
\hline Prospective & 7 & $1.39(1.13-1.72)$ & $76.1 \%,<0.001$ & \\
\hline Retrospective & 12 & $1.04(0.89-1.23)$ & $75.4 \%,<0.001$ & \\
\hline 1.4 Confounders adjusted & & & & 0.601 \\
\hline Multivariate & 15 & $1.15(1.01-1.32)$ & $87.4 \%,<0.001$ & \\
\hline Univariate & 4 & $1.30(0.93-1.81)$ & $0.0 \%, 0.841$ & \\
\hline 1.5 Quality & & & & 0.684 \\
\hline$<7$ & 8 & $1.23(0.98-1.55)$ & $44.3 \%, 0.083$ & \\
\hline$\geq 7$ & 11 & $1.14(0.97-1.33)$ & $89.9 \%,<0.001$ & \\
\hline 2. Age & 7 & $0.85(0.71-1.01)$ & $59.0 \%, 0.023$ & \\
\hline
\end{tabular}

$p$-value* for Heterogeneity; $p$-value ${ }^{\#}$ for meta regression

higher incidence of unfavorable behavioral factors, which may result in increased risk of PJI.

The impact of age has been controversial among the enrolled studies. In general, older patients are more prone to postoperative infection caused by less competent immunity [5], malnutrition status [64] and complex medical comorbidities [8]. On the contrary, a multicenter analysis of 623,253 joint replacements claimed that younger age was closely correlated with elevated PJI [40], which may be attributed to active use cycles of implants, higher possibility of infection and revision surgery [64]. Besides, another meta-analysis with 2,470,827 patients also demonstrated older age was a protective factor in TJA [18]. Interestingly, we found that age had not direct influence on risk rate of PJI $(0.85,0.71-1.01)$, which was consistent with the results concluded by Kunutsor SK et al [73]. Recently, a single-center retrospective study comprising 23,966 patients also demonstrated that age alone was not a risk factor for PJI after adjusting for confounding variables [8], indicating that other covariates should be taken into account for assessing the relationship between age and PJI. Future studies are needed to further address these findings by adequately controlling the confounders.

Previous meta-analyses have demonstrated that smoking and alcohol abuse may result in increased risk PJI. Therefore, it is of great importance to encourage smoking and alcohol cessation during peri-operation period, and some reports suggested a 4-6 week cessation prior to surgery may be effective [1]. Specifically, excessive smoking was documented as to increase incidence of infection, mainly due to impaired wound-healing capacity, disrupted immune response, as well as nicotine or carbon monoxide-mediated vasoconstriction, soft-tissue hypo-perfusion, hypoxia, and thrombi formation [1]. While alcohol could affect the immune system and contribute to impaired phagocytic function [64]. In addition, alcohol abuse is a deleterious factor for developing cirrhosis, which may in turn increase risk of infection [64]. Intriguing, our pooled results showed that smoking and alcohol abuse were not correlated with PJI following THA. However, it should be noted that smoking may contribute to synergistic effect on elevated risk of PJI (3.54-fold) for patients with obesity [4, 74]. Accordingly, caution is still warranted when considering a THA in tobacco and alcohol users. More trials are still needed to extensively elucidate the underlying mechanism between smoking/ alcohol abuse and PJI.

It is imperative that both the surgeons and patients understand and identify the modifiable risk factors prior to THA so that they could make prudent decisions in the perioperative management, mitigate the risk of PJI, and therefore decrease the enormous financial and social burden of PJI $[1,9]$. The findings in this meta-analysis, along with advanced diagnostic and treatment approaches, will allow the development of prevention 
Table 4 Medical history characteristics for periprosthetic joint infection and the outcomes of meta-analysis

\begin{tabular}{|c|c|c|c|c|}
\hline Comparisons & $\begin{array}{l}\text { Number of } \\
\text { studies }\end{array}$ & RR $(95 \% \mathrm{Cl})$ & $\begin{array}{l}\text { Heterogeneity } \\
I^{2}, p \text {-value* }\end{array}$ & $p$-value ${ }^{\#}$ \\
\hline 1. DM vs. non-DM & 15 & $1.64(1.25-2.21)$ & $93.5 \%,<0.001$ & \\
\hline 1.1 Location & & & & 0.079 \\
\hline North America & 7 & $1.28(0.79-2.07)$ & $96.5 \%,<0.001$ & \\
\hline Asia-Pacific & 4 & $1.84(1.34-2.53)$ & $0.0 \%, 0.434$ & \\
\hline Europe & 4 & $2.59(1.17-5.74)$ & $68.8 \%, 0.022$ & \\
\hline 1.2 Follow-up years & & & & 0.253 \\
\hline$\geq 3$ & 5 & $1.24(0.97-1.57)$ & $38.9 \%, 0.162$ & \\
\hline$<3$ & 10 & $1.94(1.28-2.93)$ & $94.1 \%,<0.001$ & \\
\hline 1.3 Design & & & & 0.942 \\
\hline Prospective & 5 & $1.56(1.09-2.25)$ & $47.9 \%, 0.104$ & \\
\hline Retrospective & 10 & $1.64(1.09-2.46)$ & $94.7 \%,<0.001$ & \\
\hline 1.4 Confounders adjusted & & & & 0.387 \\
\hline Multivariate & 9 & $1.45(1.00-2.11)$ & $96.1 \%,<0.001$ & \\
\hline Univariate & 6 & $2.01(1.28-3.16)$ & $50.1 \%, 0.075$ & \\
\hline 2. AVN vs. non & 2 & $1.65(1.07-2.56)$ & $53.9 \%, 0.141$ & \\
\hline 3. femoral neck fracture vs. non & 2 & $1.75(1.39-2.20)$ & $0.0 \%, 0.378$ & \\
\hline 4. RA vs. non & 8 & $1.37(1.23-1.54)$ & $0.0 \%, 0.621$ & \\
\hline 5. CVD vs. non & 8 & $1.34(1.03-1.74)$ & $61.8 \%, 0.010$ & \\
\hline 6. Chronic pulmonary disease vs. non & 2 & $1.22(1.08-1.37)$ & $0.0 \%, 0.897$ & \\
\hline 7. Neurological diseases vs. non & 3 & $1.19(1.05-1.35)$ & $27.8 \%, 0.250$ & \\
\hline 8. Opioid use vs. non & 3 & $1.53(1.35-1.73)$ & $49.6 \%, 0.137$ & \\
\hline 9. IDA vs. non & 2 & $1.15(1.13-1.17)$ & $95 \%,<0.001$ & \\
\hline 10. Dysplasia or dislocation vs. non & 2 & $0.65(0.45-0.93)$ & $0.0 \%, 0.885$ & \\
\hline 11. OA vs. non & 4 & $0.70(0.62-0.79)$ & $0.0 \%, 0.479$ & \\
\hline 12. Previous joint surgery vs. non & 4 & $2.69(0.67-10.72)$ & $83.6 \%,<0.001$ & \\
\hline 13. Renal disease vs. non & 4 & $1.33(0.50-3.53)$ & $98.7 \%,<0.001$ & \\
\hline 14. Hypertension vs. non & 3 & $1.17(0.94-1.46)$ & $34.6 \%, 0.217$ & \\
\hline 15. Cancer vs. non & 2 & $1.06(0.87-1.29)$ & $0.0 \%, 0.486$ & \\
\hline 16. Steroid use vs. non & 6 & $1.80(0.89-3.63)$ & $9.2 \%, 0.357$ & \\
\hline 17. Liver disease vs. non & 2 & $1.73(0.86-3.51)$ & $94.0 \%,<0.001$ & \\
\hline
\end{tabular}

$p$-value* for Heterogeneity; $p$-value ${ }^{\#}$ for meta regression; $A V N$ Avascular necrosis, $C V D$ Cardiac vascular disease, DM Diabetes, IDA Iron-deficiency anemia, $O A$ Osteoarthritis, RA Rheumatoid arthritis, IDA Iron-deficiency anemia

strategies and increase the adherence to the clinical practice. Taken together, these results may offer help in developing guidelines on prevention of PJI after THA, and eventually establishing strategies to control it.

In addition to the factors discussed above, preoperative and intraoperative factors also play important roles. Nasal Staphylococcus aureus (S. aureus) decolonization by the strategies of antibiotic prophylaxis has been widely used to prevent PJI before THA. The influence of preoperative decolonization on PJI was discussed in a recent meta-analysis including 36,000 cases of primary THA and TKA. S. aureus screening and decolonization prior to primary THA were associated with a significantly decreased risk of surgical site infections and PJI [75]. Moreover, whether the fixation method influences the risk of PJI following THR is still controversial. A recent meta-analysis reported that all kinds of cemented fixations including plain, antibiotic and hybrid were each associated with an increased PJI risk when compared with uncemented fixations. In cemented fixations group, plain cemented fixations increased PJI risk compared to antibiotic-loaded cemented fixations [76, 77]. Furthermore, different prosthetic bearing surface materials may influence the risk of PJI after THA. A previous meta-analysis comprised 11 randomized controlled trials and six observational studies until September 2016 


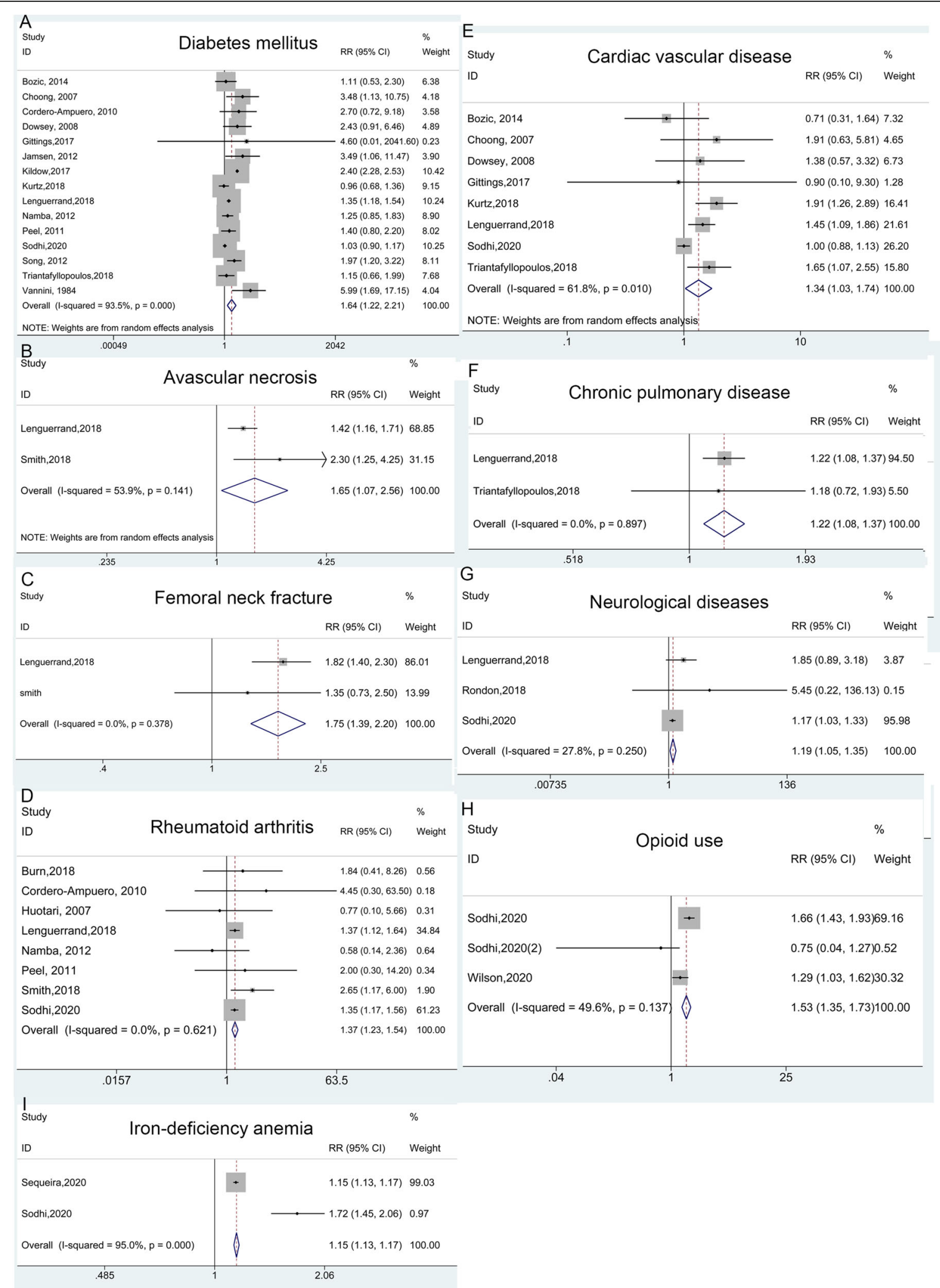

Fig. 4 Forest plots of the meta-analysis of medical history characteristics, including diabetes mellitus (A), avascular necrosis (B), femoral neck fracture $(\mathbf{C})$, rheumatoid arthritis $(\mathbf{D})$, cardiac vascular disease $(\mathbf{E})$, chronic pulmonary disease $(\mathbf{F})$, neurological diseases $(\mathbf{G})$, opioid use $(\mathbf{H})$ and irondeficiency anemia (I) as risk factors for PJI following THA 


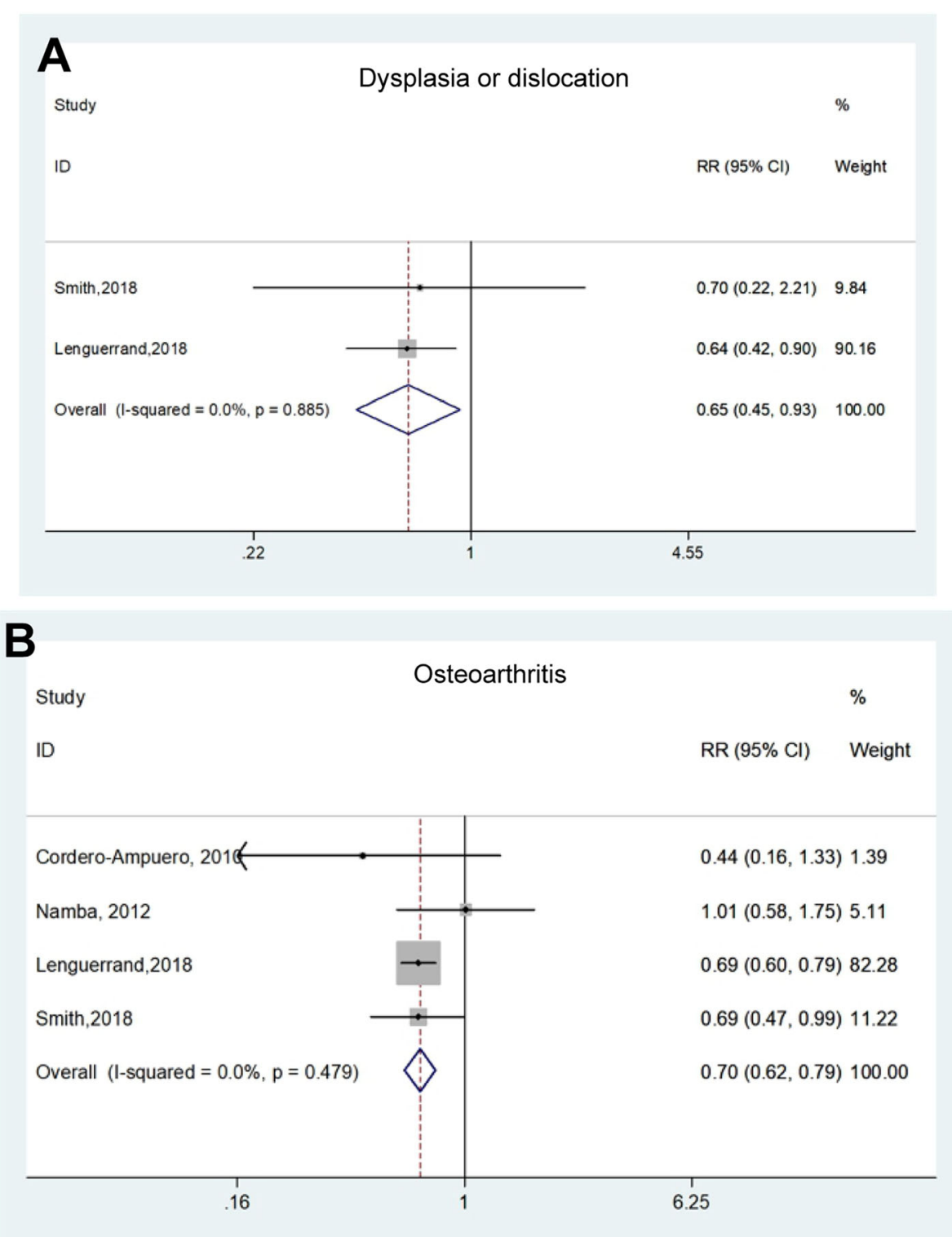

Fig. 5 Forest plots of the meta-analysis of medical history characteristics, including dysplasia or dislocation (A), and osteoarthritis (B) as risk factors for PJl following THA

compared the rate of PJI between metal-on-polyethylene $(\mathrm{MoP})$, ceramic-on-polyethylene $(\mathrm{CoP})$, and ceramic-onceramic $(\mathrm{CoC})$ bearings. It showed no significant difference between the three bearing combinations in terms of risk of PJI [78]. Although no bearing surfaces can deny the risk currently, subsequent articles containing large amounts of data have found that ceramic surfaces could reduce risk are convincing [40, 79, 80]. In addition, a prospective observational cohort study analyzing 623253 primary THA investigated lateral surgical approach was associated with the increased risk of PJI from 3 months onwards patients compared to posterior surgical approach, due to the increased tissue damage and bleeding, probably [40].

However, it should be noted that some limitations remain to be addressed. First, most of the studies were retrospective, giving rise to a comparative low quality of evidence as per the NOS score. In addition, high proportion of retrospective studies would lead to inherent bias inevitably [81]. Second, number of included hips among the selected studies ranged from 33 to $1,158,742$, the inclusion of these studies may lead to bias and confounding within our results. Third, some of the comparison like AVN of femoral head, femoral neck fracture, 


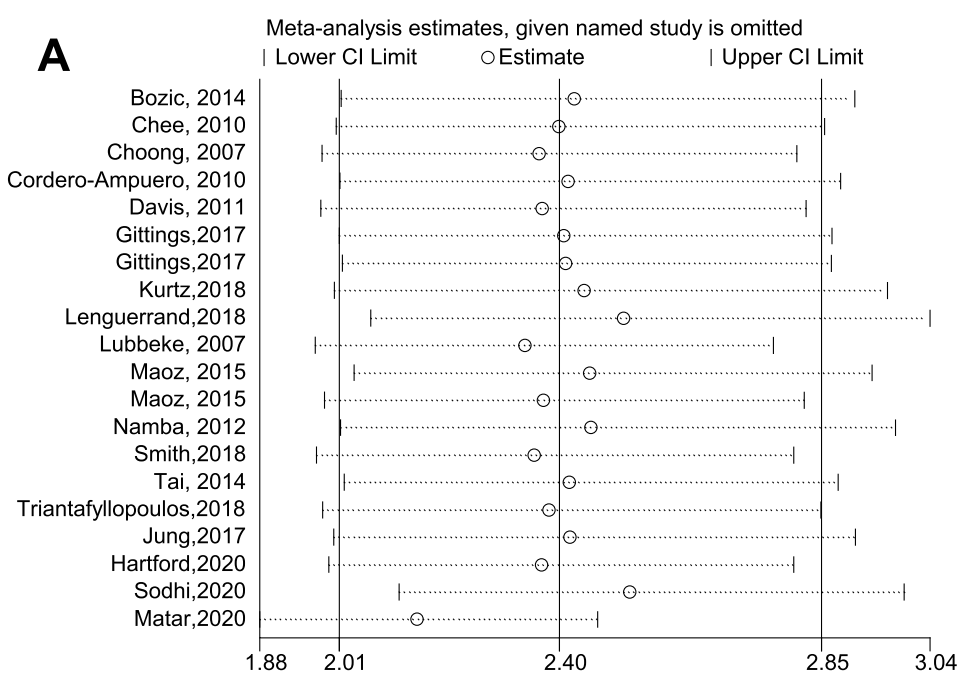

B Begg's funnel plot with pseudo $95 \%$ confidence limits

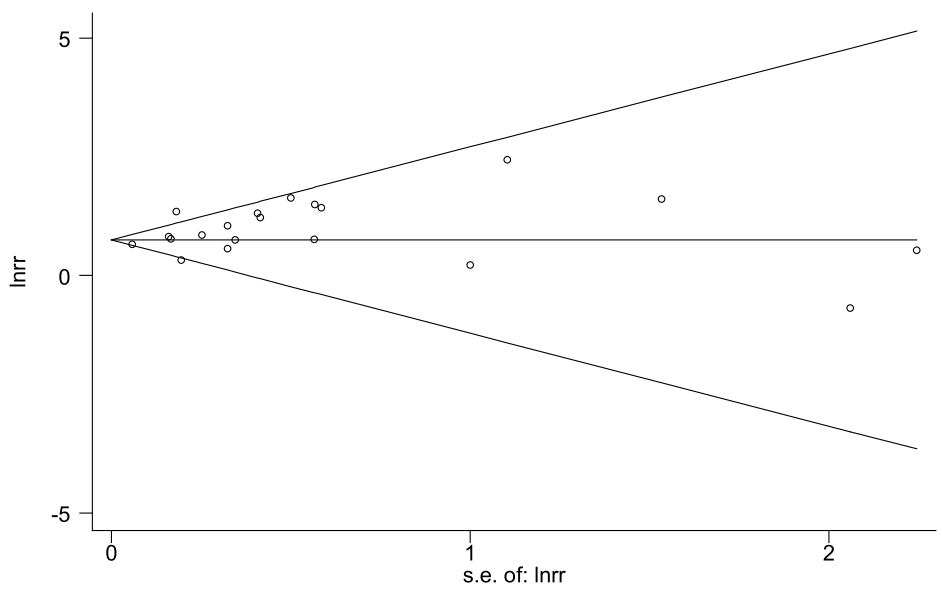

C Filled funnel plot with pseudo $95 \%$ confidence limits

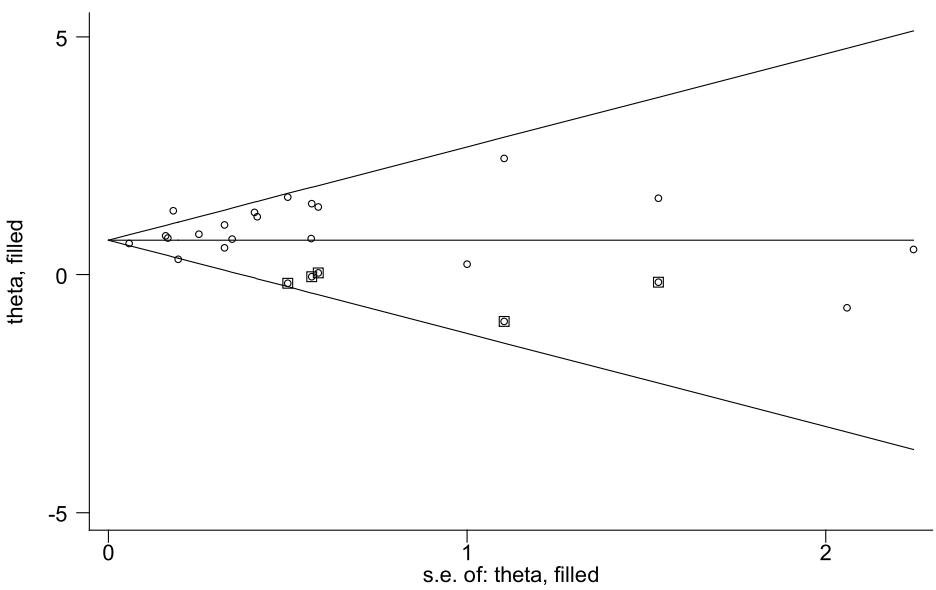

Fig. 6 Sensitivity analysis (A), and Begg's funnel plot (B) of the outcome: BMI. Funnel plot after modified with trimmed and filled method (C) of the outcome: BMI 
chronic pulmonary disease, IDA, dysplasia or dislocation of hip, cancer and liver disease included 2 studies only, respectively. It might limit the meaning of these pooled result. Fourth, the RRs were not adjusted to include more participants. Fifth, the follow-up time was heterogeneous among studies with a range from 0.25 to 10 years and did not differentiate time of onset of infection after primary arthroplasty. Sixth, the included studies were performed between 1983 to 2020. The THA operation technology in different period was significantly different, especially in two studies in 1983 and 1984.This maybe a reason for the bias of this meta-analysis. Seventh, the races vary among the selected studies, which may lead to discrepancies between various studies [64]. Lastly, another relevant issue and potential confounder of the results was the different diagnostic tools for PJI used in the original studies and the lack of a risk factor definition in the eligible studies, except for obesity was defined as BMI.

\section{Conclusion}

Taken together, this meta-analysis identified significant risk factors for PJI associated with THA are high BMI, DM, AVN, femoral neck fracture, RA, CVD, chronic pulmonary disease, neurological disease, opioid use and IDA while protective factors include female gender, OA and dysplasia/ dislocation. We therefore suggest optimization of modifiable risk factors such as BMI for reducing the risk of PJI in clinical practice.

\section{Abbreviations \\ AVN: Avascular necrosis; Cls: Corresponding intervals; CVD: Cardiovascular disease; DM: Diabetes mellitus; MOOSE: Meta-analysis of Observational Studies in Epidemiology; NOS: Newcastle-Ottawa Scale; OA: Osteoarthritis; ORs: Odds ratio; PJI: Periprosthetic joint infection; PRISMA: Preferred Reporting Items for Systematic reviews and Meta-Analysis; RA: Rheumatoid arthritis; RRs: Risk ratios; TAA: Total ankle arthroplasty; TKA: Total knee arthroplasty; THA: Total hip arthroplasty; THR: Total hip replacement}

\section{Supplementary Information}

The online version contains supplementary material available at https://doi. org/10.1186/s12891-021-04647-1.

Additional file 1: Figure S1. Subgroup analysis for gender with different location (A), Follow-up years (B), or confounders adjusted (C) were shown to identify the possible association between gender with PJ following THA. Sensitivity analysis (D), Begg's funnel plot (E) of the outcome: gender. Figure S2. Subgroup analysis for diabetes mellitus (DM) with different location (A), Follow-up years (B), study design (C) or confounders adjusted (D) were shown to identify the possible association between DM with PJI after THA. Begg's funnel plot (E) of the outcome: DM. Figure S3. Forest plots of the meta-analysis of medical history characteristics, including previous joint surgery $(A)$, renal disease $(B)$, hypertension $(C)$, cancer (D), steroid use (E) and liver disease (F) as risk factors for PJI following THA.

\section{Authors' contributions}

$\mathrm{XL}$ Ren designed the methodology of the study and performed the literature retrieval, data analysis and interpretation. Lin Lin contributed to the study methodology, performed the literature retrieval and data analysis. L Qi, ZY Liu and WC Zhang participated in the data analysis, and assisted in creating the figures. ZM Yang and WC Wang participated in the data interpretation, critically reviewed and revised the manuscript. ZH Li and C Tu conceptualized the study, participated in the study design, data interpretation, and manuscript revision. All authors read and approved the final manuscript as submitted.

\section{Funding}

National Natural Science Foundation of China (No. 81902745 and 82103228), Hunan Provincial Research and Development Program in Key Areas (2019WK2071, 2020DK2003), and China Postdoctoral Science Foundation (No. 2021 M693557) and Postdoctoral Program Foundation of Second Xiangya Hospital, Central South University for Dr. XL Ren.

\section{Availability of data and materials}

All data generated or analyzed during this meta-analysis were included in published article which were shown in Table 1. Comprehensive literature retrieval was performed from Pubmed, Web of Science, and the Cochrane Library. And the data from Pubmed, Web of Science, and the Cochrane Library are fully available without restriction.

\section{Declarations}

Ethics approval and consent to participate None.

\section{Consent for publication}

None.

\section{Competing interests}

We declare that we have no conflict of interest.

Received: 19 March 2021 Accepted: 21 August 2021

Published online: 12 September 2021

\section{References}

1. Eka A, Chen AF. Patient-related medical risk factors for periprosthetic joint infection of the hip and knee. Ann Transl Med. 2015;3(16):233. https://doi. org/10.3978/j.issn.2305-5839.2015.09.26.

2. Papalia R, Vespasiani-Gentilucci U, Longo UG, Esposito C, Zampogna B, Antonelli Incalzi $R$, et al. Advances in management of periprosthetic joint infections: an historical prospective study. Eur Rev Med Pharmacol Sci. 2019; 23(2 Suppl):129-38. https://doi.org/10.26355/eurrev_201904_17482.

3. Bozic KJ, Ong K, Lau E, Berry DJ, Vail TP, Kurtz SM, et al. Estimating risk in Medicare patients with THA: an electronic risk calculator for periprosthetic joint infection and mortality. Clin Orthop Relat Res. 2013;471(2):574-83. https://doi.org/10.1007/s11999-012-2605-z.

4. Xu C, Guo H, Wang Q, Qu P, Bell K, Chen J. Interaction of obesity with smoking and inflammatory arthropathies increases the risk of periprosthetic joint infection: a propensity score matched study in a Chinese Han population. J Hosp Infection. 2019;101(2):222-8. https://doi.org/10.1016/j.jhin.2018.06.017.

5. Tu C, He J, Wang W, Li Z. Revision for PJI after total hip replacement: more exploration is needed. Lancet Infect Dis. 2018;18(11):1182. https://doi.org/1 0.1016/S1473-3099(18)30570-X.

6. Lee QJ, Mak WP, Wong YC. Risk factors for periprosthetic joint infection in total knee arthroplasty. J Orthop Surg. 2015;23(3):282-6. https://doi.org/1 $0.1177 / 230949901502300303$

7. Shohat N, Fleischman A, Tarabichi M, Tan TL, Parvizi J. Weighing in on body mass index and infection after Total joint arthroplasty: is there evidence for a body mass index threshold? Clin Orthop Relat Res. 2018;476(10):1964-9. https://doi.org/10.1007/s11999.0000000000000141.

8. Inoue D, Xu C, Yazdi H, Parvizi J. Age alone is not a risk factor for periprosthetic joint infection. J Hosp Infection. 2019;103(1):64-8. https://doi. org/10.1016/j.jhin.2019.04.005.

9. Girardi FM, Liu J, Guo Z, Valle AGD, MacLean C, Memtsoudis SG. The impact of obesity on resource utilization among patients undergoing total joint arthroplasty. Int Orthop. 2019;43(2):269-74. https://doi.org/10.1007/s00264018-4059-8. 
10. Cancienne JM, Werner BC, Browne JA. Is there a threshold value of hemoglobin A1C that predicts risk of infection following primary Total hip arthroplasty? J Arthroplast. 2017;32(9S):S236-40. https://doi.org/10.1016/j.a rth.2017.01.022.

11. Boni L, Kuster SP, Bartik B, Zbinden R, Zingg PO, Achermann Y. Association of Cutibacterium avidum colonization in the groin with obesity: a potential risk factor for hip Periprosthetic joint infection. Clin Infect Dis. 2018;67(12): 1878-82. https://doi.org/10.1093/cid/ciy379.

12. Dowsey MM, Choong PF. Obesity is a major risk factor for prosthetic infection after primary hip arthroplasty. Clin Orthop Relat Res. 2008;466(1): 153-8. https://doi.org/10.1007/s11999-007-0016-3.

13. Tu C, Wang W, Li Z. Letter to the editor concerning the paper "long-term outcome of total knee arthroplasty in morbid obesity patients". Int Orthop. 2019;44(1):105-6. https://doi.org/10.1007/s00264-019-04410-1.

14. Jamsen E, Nevalainen P, Eskelinen A, Huotari K, Kalliovalkama J, Moilanen T. Obesity, diabetes, and preoperative hyperglycemia as predictors of periprosthetic joint infection: a single-center analysis of 7181 primary hip and knee replacements for osteoarthritis. J Bone Joint Surg Am. 2012;94(14): e101. https://doi.org/10.2106/JBJS.J.01935.

15. Vannini P, Ciavarella A, Olmi R, Flammini M, Moroni A, Galuppi V, et al. Diabetes as pro-infective risk factor in total hip replacement. Acta Diabetol Lat. 1984;21(3):275-80. https://doi.org/10.1007/BF02642901.

16. Kildow BJ, Agaba P, Moore BF, Hallows RK, Bolognesi MP, Seyler TM. Postoperative Impact of Diabetes, Chronic Kidney Disease, Hemodialysis, and Renal Transplant After Total Hip Arthroplasty. J Arthroplasty. 2017;32(9s): S135-S140.e131.

17. Kwon SS, Kwon JY, Park YW, Kim YH, Lim JB. HbA1c for diagnosis and prognosis of gestational diabetes mellitus. Diabetes Res Clin Pract. 2015; 110(1):38-43. https://doi.org/10.1016/j.diabres.2015.07.014.

18. Resende VAC, Neto AC, Nunes C, Andrade R, Esprequeira-Mendes J, Lopes S. Higher age, female gender, osteoarthritis and blood transfusion protect against periprosthetic joint infection in total hip or knee arthroplasties: a systematic review and meta-analysis. Knee Surg Sports Traumatol Arthrosc. 2018;29(1):8-43. https://doi.org/10.1007/s00167-018-5231-9.

19. Burn E, Edwards CJ, Murray DW, Silman A, Cooper C, Arden NK, et al. The impact of rheumatoid arthritis on the risk of adverse events following joint replacement: a real-world cohort study. Clin Epidemiol. 2018;10:697-704. https://doi.org/10.2147/CLEP.S160347.

20. Ravi B, Escott B, Shah PS, Jenkinson R, Chahal J, Bogoch E, et al. A systematic review and meta-analysis comparing complications following total joint arthroplasty for rheumatoid arthritis versus for osteoarthritis. Arthritis Rheum. 2012;64(12):3839-49. https://doi.org/10.1002/art.37690.

21. Hanson CG, Barner KL, Rose-Reneau Z, Kortz M. The impact of chronic obstructive pulmonary disease and hospital teaching status on mortality, cost, and length of stay in elective Total hip arthroplasty patients. Cureus. 2019;11(4):e4443. https://doi.org/10.7759/cureus.4443.

22. Page MJ, McKenzie JE, Bossuyt PM, Boutron I, Hoffmann TC, Mulrow CD et al. The PRISMA 2020 statement: an updated guideline for reporting systematic reviews. BMJ. 2021;372:n71.

23. Stroup DF, Berlin JA, Morton SC, Olkin I, Williamson GD, Rennie D, et al. Meta-analysis of observational studies in epidemiology - a proposal for reporting. Jama-J Am Med Assoc. 2000;283(15):2008-12. https://doi.org/10.1 001/jama.283.15.2008.

24. Zhang C, Ren X, He J, Wang W, Tu C, Li Z. The prognostic value of long noncoding RNA SNHG16 on clinical outcomes in human cancers: a systematic review and meta-analysis. Cancer Cell Int. 2019;19(1):261. https:// doi.org/10.1186/s12935-019-0971-2.

25. Surin W, Sundholm K, Backman L. Infection after total hip replacement. With special reference to a discharge from the wound. J Bone Joint Surg Br. 1983;65(4):412-8.

26. Yong KS, Kareem BA, Ruslan GN, Harwant S. Risk factors for infection in total hip replacement surgery at Hospital Kuala Lumpur. Med J Malaysia. 2001; 56(Suppl C):57-60

27. Bozic KJ, Ward DT, Lau EC, Chan V, Wetters NG, Naziri Q, et al. Risk factors for periprosthetic joint infection following primary total hip arthroplasty: a case control study. J Arthroplast. 2014;29(1):154-6. https://doi.org/10.1016/j.a rth.2013.04.015.

28. Chee YH, Teoh KH, Sabnis BM, Ballantyne JA, Brenkel IJ. Total hip replacement in morbidly obese patients with osteoarthritis results of a prospectively matched study. J Bone Joint Surg Br. 2010;92b(8):1066-71.
29. Choong PFM, Dowsey MM, Carr D, Daffy J, Stanley P. Risk factors associated with acute hip prosthetic joint infections and outcome of treatment with a rifampin-based regimen. Acta Orthop. 2007;78(6):755-65. https://doi.org/10.1 080/17453670710014527.

30. Cordero-Ampuero J, de Dios M. What are the risk factors for infection in hemiarthroplasties and total hip arthroplasties? Clin Orthop Relat Res. 2010; 468(12):3268-77. https://doi.org/10.1007/s11999-010-1411-8.

31. Dale H, Skramm I, Lower HL, Eriksen HM, Espehaug B, Furnes O, et al. Infection after primary hip arthroplasty a comparison of 3 Norwegian health registers. Acta Orthop. 2011;82(6):646-54. https://doi.org/10.3109/17453674.2 011.636671 .

32. Davis AM, Wood AM, Keenan ACM, Brenkel IJ, Ballantyne JA. Does body mass index affect clinical outcome post-operatively and at five years after primary unilateral total hip replacement performed for osteoarthritis? A multivariate analysis of prospective data. J Bone Joint Surg Br. 2011;93b(9): 1178-82.

33. de Boer AS, Geubbels EL, Wille J, Mintjes-de Groot AJ. Risk assessment for surgical site infections following total hip and total knee prostheses. J Chemother. 2001;1(1):42-7.

34. Gittings DJ, Courtney PM, Ashley BS, Hesketh PJ, Donegan DJ, Sheth NP. Diagnosing infection in patients undergoing conversion of prior internal fixation to Total hip arthroplasty. J Arthroplast. 2017;32(1):241-5. https://doi. org/10.1016/j.arth.2016.06.047.

35. Gonzalez Al, Luime JJ, Uckay I, Hannouche D, Hoffmeyer P, Lubbeke A. Is there an association between smoking status and prosthetic joint infection after primary Total joint arthroplasty? J Arthroplast. 2018;33(7):2218-24. https://doi.org/10.1016/j.arth.2018.02.069.

36. Hartford JM, Graw BP, Frosch DL. Perioperative complications stratified by body mass index for the direct anterior approach to Total hip arthroplasty. J Arthroplast. 2020;35(9):2652-7. https://doi.org/10.1016/j.arth.2020.04.018.

37. Huotari K, Lyytikainen O, Seitsalo S, Hospital infection surveillance T. Patient outcomes after simultaneous bilateral total hip and knee joint replacements. J Hosp Infect. 2007;65(3):219-25. https://doi.org/10.1016/j.jhin.2006.10.018.

38. Jung P, Morris AJ, Zhu M, Roberts SA, Frampton C, Young SW. BMI is a key risk factor for early periprosthetic joint infection following total hip and knee arthroplasty. New Zealand Med J. 2017;130(1461):24-34.

39. Kurtz SM, Lau EC, Son MS, Chang ET, Zimmerli W, Parvizi J. Are we winning or losing the Battle with Periprosthetic joint infection: trends in Periprosthetic joint infection and mortality risk for the Medicare population. J Arthroplast. 2018;33(10):3238-45. https://doi.org/10.1016/j.arth.2018.05.042.

40. Lenguerrand E, Whitehouse MR, Beswick AD, Kunutsor SK, Burston B, Porter M, et al. Risk factors associated with revision for prosthetic joint infection after hip replacement: a prospective observational cohort study. Lancet Infect Dis. 2018;18(9): 1004-14. https:/doi.org/10.1016/S1473-3099(18)30345-1.

41. Lubbeke A, Stern R, Garavaglia G, Zurcher L, Hoffmeyer P. Differences in outcomes of obese women and men undergoing primary total hip arthroplasty. Arthrit Rheum-Arthr. 2007;57(2):327-34. https://doi.org/10.1 002/art.22542

42. Maoz G, Phillips M, Bosco J, Slover J, Stachel A, Inneh I, et al. The Otto Aufranc award: modifiable versus nonmodifiable risk factors for infection after hip arthroplasty. Clin Orthop Relat Res. 2015;473(2):453-9. https://doi. org/10.1007/s11999-014-3780-x.

43. van Kasteren Marjo EE, Manniën J, Ott A, Kullberg B-J, de Boer AS, Gyssens IC. Antibiotic prophylaxis and the risk of surgical site infections following total hip arthroplasty: timely administration is the most important factor. Clin Infect Dis. 2007:44(7):921-7.

44. Matar HE, Pincus D, Paterson JM, Aktar S, Jenkinson R, Ravi B. Early surgical complications of Total hip arthroplasty in patients with morbid obesity: propensity-matched cohort study of 3683 patients. J Arthroplast. 2020;35(9): 2646-51. https://doi.org/10.1016/j.arth.2020.04.044.

45. McIntosh ALHA, Wenger DE, Osmon DR. Recent intraarticular steroid injection may increase infection rates in primary THA. Clin Orthop Related Res. 2006;451:50-4. https://doi.org/10.1097/01.blo.0000229318.51254.79.

46. Meermans $\mathrm{G}$, Corten $\mathrm{K}$, Simon JP. Is the infection rate in primary THA increased after steroid injection? Clin Orthop Relat Res. 2012;470(11):3213-9. https://doi.org/10.1007/s11999-012-2390-8.

47. Muilwijk J, Walenkamp GH, Voss A, Wille JC, van den Hof S. Random effect modelling of patient-related risk factors in orthopaedic procedures: results from the Dutch nosocomial infection surveillance network 'PREZIES'. J Hosp Infect. 2006;62(3):319-26. https://doi.org/10.1016/j.jhin.2005.08.006. 
48. Namba RS, Inacio MC, Paxton EW. Risk factors associated with surgical site infection in 30,491 primary total hip replacements. J Bone Joint Surg Br. 2012;94(10):1330-8.

49. Ong KL, Kurtz SM, Lau E, Bozic KJ, Berry DJ, Parvizi J. Prosthetic joint infection risk after Total hip arthroplasty in the Medicare population. J Arthroplasty. 2009;24(6):105-9. https://doi.org/10.1016/j.arth.2009.04.027.

50. Peel TN, Dowsey MM, Daffy JR, Stanley PA, Choong PF, Buising KL. Risk factors for prosthetic hip and knee infections according to arthroplasty site. J Hosp Infect. 2011;79(2):129-33. https://doi.org/10.1016/j.jhin.2011.06.001.

51. Rondon AJ, Tan TL, Schlitt PK, Greenky MR, Phillips JL, Purtill JJ. Total joint arthroplasty in patients with Parkinson's disease: survivorship, outcomes, and reasons for failure. J Arthroplast. 2018;33(4):1028-32. https://doi.org/10.1 016/j.arth.2017.11.017.

52. Sequeira SB, Labaran LA, Bell JE, Amin RM, Rao SS, Werner BC. Compensated Cirrhosis Is Associated With Increased Risk of Complications Following Total Hip Arthroplasty in a Large Medicare Database. J Arthroplasty. 2020;36(4): 1361-1366.e1. https://doi.org/10.1016/j.arth.2020.10.008.

53. Sequeira SB, Quinlan ND, Althoff AD, Werner BC. Iron Deficiency Anemia is Associated with Increased Early Postoperative Surgical and Medical Complications Following Total Hip Arthroplasty. J Arthroplasty. 2020;36(3): 1023-8. https://doi.org/10.1016/j.arth.2020.09.043.

54. Smith JO, Frampton CMA, Hooper GJ, Young SW. The impact of patient and surgical factors on the rate of postoperative infection after Total hip arthroplasty-a New Zealand joint registry study. J Arthroplast. 2018;33(6): 1884-90. https://doi.org/10.1016/j.arth.2018.01.021.

55. Sodhi N, Anis HK, Acuna AJ, Vakharia RM, Gold PA, Garbarino LJ, et al. Opioid use disorder is associated with an increased risk of infection after Total joint arthroplasty: a large database study. Clin Orthop Relat Res. 2020; 478(8):1752-9. https://doi.org/10.1097/CORR.0000000000001390.

56. Sodhi N, Anis HK, Vakharia RM, Acuna AJ, Gold PA, Garbarino LJ, et al. What are risk factors for infection after primary or revision Total joint arthroplasty in patients older than 80 years? Clin Orthop Relat Res. 2020;478(8):1741-51. https://doi.org/10.1097/CORR.0000000000001389.

57. Song KH, Kim ES, Kim YK, Jin HY, Jeong SY, Kwak YG, et al. Differences in the risk factors for surgical site infection between total hip arthroplasty and total knee arthroplasty in the Korean nosocomial infections surveillance system (KONIS). Infect Control Hosp Epidemiol. 2012;33(11):1086-93. https:// doi.org/10.1086/668020.

58. Tai SM, Imbuldeniya AM, Munir S, Walter WL, Walter WK, Zicat BA. The effect of obesity on the clinical, functional and radiological outcome of Cementless Total hip replacement: a case-matched study with a minimum 10-year follow-up. J Arthroplasty. 2014;29(9):1758-62. https://doi.org/10.101 6/j.arth.2014.04.033.

59. Triantafyllopoulos GK, Soranoglou VG, Memtsoudis SG, Sculco TP, Poultsides LA. Rate and risk factors for Periprosthetic joint infection among 36,494 primary Total hip arthroplasties. J Arthroplast. 2018;33(4):1166-70. https:// doi.org/10.1016/j.arth.2017.11.040.

60. Wilson JM, Farley KX, Erens GA, Bradbury TL, Guild GN 3rd. Preoperative opioid use is a risk factor for complication following revision total hip arthroplasty. Hip Intern. 2020; 1120700020947400. https://doi.org/10.11 77/1120700020947400.

61. Malinzak RA, Ritter MA, Berend ME, Meding JB, Olberding EM, Davis KE. Morbidly obese, diabetic, younger, and unilateral joint arthroplasty patients have elevated total joint arthroplasty infection rates. J Arthroplast. 2009;24(6 Suppl):84-8. https://doi.org/10.1016/j.arth.2009.05.016.

62. Zingg M, Miozzari HH, Fritschy D, Hoffmeyer P, Lubbeke A. Influence of body mass index on revision rates after primary total knee arthroplasty. Int Orthop. 2016;40(4):723-9. https://doi.org/10.1007/s00264-015-3031-0.

63. Everhart JS, Altneu E, Calhoun JH. Medical comorbidities are independent preoperative risk factors for surgical infection after total joint arthroplasty. Clin Orthop Relat Res. 2013;471(10):3112-9. https://doi.org/10.1007/s11999013-2923-9.

64. Wu C, Qu X, Liu F, Li H, Mao Y, Zhu Z. Risk factors for periprosthetic joint infection after total hip arthroplasty and total knee arthroplasty in Chinese patients. PLoS One. 2014;9(4):e95300. https://doi.org/10.1371/journal.pone. 0095300.

65. Lovecchio FC, Manalo JP, Demzik A, Sahota S, Beal M, Manning D. Avascular necrosis is associated with increased transfusions and readmission following primary Total hip arthroplasty. Orthopedics. 2017;40(3):171-6. https://doi. org/10.3928/01477447-20170117-03
66. Eskildsen SM, Kamath GV, Del Gaizo DJ. Age matters when comparing hemiarthroplasty and total hip arthroplasty for femoral neck fractures in Medicare patients. Hip Intern. 2019;29(6):674-9. https://doi.org/10.1177/112 0700018816924.

67. Pedersen $A B$, Svendsson JE, Johnsen SP, Riis A, Overgaard S. Risk factors for revision due to infection after primary total hip arthroplasty. A populationbased study of 80,756 primary procedures in the Danish hip arthroplasty registry. Acta Orthop. 2010;81(5):542-7. https://doi.org/10.3109/17453674.2 010.519908.

68. Mayers W, Schwartz B, Schwartz A, Moretti V, Goldstein W, Shah R. National trends and in hospital outcomes for total hip arthroplasty in avascular necrosis in the United States. Int Orthop. 2016;40(9):1787-92. https://doi. org/10.1007/s00264-015-3089-8.

69. Bozic KJ, Lau E, Kurtz S, Ong K, Rubash H, Vail TP, et al. Patient-related risk factors for periprosthetic joint infection and postoperative mortality following total hip arthroplasty in Medicare patients. J Bone Joint Surg Am. 2012;94(9):794-800. https://doi.org/10.2106/JBJS.K.00072.

70. Althoff A, Cancienne JM, Cooper MT, Werner BC. Patient-related risk factors for Periprosthetic ankle joint infection: an analysis of 6977 Total ankle arthroplasties. J Foot Ankle Surg. 2018;57(2):269-72. https://doi.org/10.1053/j. jfas.2017.09.006.

71. Smyth NA, Kennedy JG, Parvizi J, Schon LC, Aiyer AA. Risk factors for periprosthetic joint infection following total ankle replacement. Foot Ankle Surg. 2019; 26(5):591-5. https://doi.org/10.1016/j.fas.2019.07.015.

72. Ridgeway S, Wilson J, Charlet A, Kafatos G, Pearson A, Coello R. Infection of the surgical site after arthroplasty of the hip. J Bone Joint Surg Br. 2005; 87(6):844-50.

73. Kunutsor SK, Whitehouse MR, Blom AW, Beswick AD, Team I. Patient-related risk factors for Periprosthetic joint infection after Total joint arthroplasty: a systematic review and Meta-analysis. PLoS One. 2016;11(3):e0150866. https://doi.org/10.1371/journal.pone.0150866.

74. Crowe B, Payne A, Evangelista PJ, Stachel A, Phillips MS, Slover JD, et al. Risk factors for infection following Total knee arthroplasty: a series of 3836 cases from one institution. J Arthroplast. 2015;30(12):2275-8. https://doi.org/10.101 6/j.arth.2015.06.058.

75. Zhu X, Sun X, Zeng Y, Feng W, Li J, Zeng J, et al. Can nasal Staphylococcus aureus screening and decolonization prior to elective total joint arthroplasty reduce surgical site and prosthesis-related infections? A systematic review and meta-analysis. J Orthop Surg Res. 2020;15(1):60. https://doi.org/10.1186/ s13018-020-01601-0.

76. Kunutsor SK, Beswick AD, Whitehouse MR, Blom AW, Lenguerrand E. Implant Fixation and Risk of Prosthetic Joint Infection Following Primary Total Hip Replacement: Meta-Analysis of Observational Cohort and Randomised Intervention Studies. J Clin Med. 2019:8(5):722.

77. Sebastian S, Liu Y, Christensen R, Raina DB, Tagil M, Lidgren L. Antibiotic containing bone cement in prevention of hip and knee prosthetic joint infections: a systematic review and meta-analysis. J Orthop Translat. 2020;23: 53-60. https://doi.org/10.1016/j.jot.2020.04.005

78. Hexter AT, Hislop SM, Blunn GW, Liddle AD. The effect of bearing surface on risk of periprosthetic joint infection in total hip arthroplasty: a systematic review and meta-analysis. Bone Joint J. 2018;100-b(2):134-42.

79. Madanat R, Laaksonen I, Graves SE, Lorimer M, Muratoglu O, Malchau H. Ceramic bearings for total hip arthroplasty are associated with a reduced risk of revision for infection. Hip Intern. 2018;28(3):222-6. https://doi.org/1 $0.1177 / 1120700018776464$

80. Pitto RP, Sedel L. Periprosthetic joint infection in hip arthroplasty: is there an association between infection and bearing surface type? Clin Orthop Relat Res. 2016;474(10):2213-8. https://doi.org/10.1007/s11999-016-4916-y.

81. Guo W, Lu X, Liu Q, Zhang T, Li P, Qiao W, et al. Prognostic value of neutrophil-to-lymphocyte ratio and platelet-to-lymphocyte ratio for breast cancer patients: an updated meta-analysis of 17079 individuals. Cancer Med. 2019;8(9):4135-48. https://doi.org/10.1002/cam4.2281.

\section{Publisher's Note}

Springer Nature remains neutral with regard to jurisdictional claims in published maps and institutional affiliations. 